VOLOTÃO, Jaqueline dos Santos. Os Direitos Humanos e Mulheres Vítimas de Violência Doméstica em tempos de pandemia. Dignidade Re-Vista, v.7, n.12, jul 2021.

\title{
Os Direitos Humanos e Mulheres Vítimas de Violência Doméstica em tempos de pandemia
}

Human Rights and women victims of domestic violence in pandemic times

\section{Jaqueline dos Santos Volotão}

jaquelinevolotao13@gmail.com

Graduanda em Serviço Social pela PUC

Rio. Servidora Pública do Núcleo de

Defesa da Mulher Vítima de Violência

de Gênero na Defensoria Pública do

Estado do Rio de Janeiro.

\section{Resumo}

$\mathrm{O}$ presente artigo tem o intuito de trazer um questionamento sobre o alto número de atendimentos realizados pelo Núcleo Especial de Direito da Mulher e de Vítimas da Violência no Estado do Rio de Janeiro (NUDEM) em tempos de pandemia e a violação dos Direitos Humanos frente à violência sofrida. Aumentou o número de casos ou as mulheres estão mais instruídas quanto ao rompimento do ciclo de violência?

Palavras-chave: NUDEM; feminicídio; leis de proteção às mulheres; igualdade de gênero.

\begin{abstract}
This article aims to raise a question about the high number of assistance provided by the Special Center for Women's Rights and Victims of Violence in the State of Rio de Janeiro (NUDEM) in times of Pandemic and the violation of Human Rights in the face of violence suffered. Has the number of cases increased or are women better educated about breaking the cycle of violence?
\end{abstract}

Keywords: NUDEM; women's protection laws; gender equality 


\section{Introdução}

A pandemia da Covid-19 trouxe muitas reflexões quanto à saúde mundial, o agravamento das desigualdades, aumento da violência de diferentes formas, mas também sobre a violência doméstica contra a mulher e sua história nas sociedades.

A relação da representação da mulher na sociedade vem se modificando a passos curtos, principalmente se voltarmos nosso olhar para a Grécia Antiga, época em que predominava a dominação masculina justificada pelas formas anatômicas, onde a mulher era um ser frágil e necessitava da proteção masculina, sendo esse considerado seu guardião. O homem era responsável por sua vida, limitando seus direitos cíveis, além de serem consideradas juridicamente incapazes (Bérquo, 2014).

Pensando no tanto tempo da dominação masculina e no tão pouco tempo de revolução feminina, podemos considerar que ainda existe uma expressão forte na desigualdade das relações sociais na perspectiva de gênero. Com isso, o rompimento do tabu da violência contra mulher ainda está engatinhando nessa linha do tempo, mesmo com todos os avanços e conquistas femininas.

Ainda assim, vivemos em uma sociedade na qual o processo de diferenciação entre gêneros ocorre por sua forma tradicionalista e patriarcal, em que as mulheres são consideradas extensão das posses e da honra de "seus homens", estabelecendo a desigualdade de valor entre as pessoas. É comum os discursos de manifestação da violência masculina serem sinônimo de virilidade e superioridade frente ao sexo frágil (mulher).

O Direito Internacional dos Direitos Humanos surgiu após a II Grande Guerra com intuito de garantir que nenhum ser humano tivesse seus direitos violados. Os direitos fundamentais precisam da proteção do Estado para sua maior efetividade, e a Constituição de 1988 foi o marco fundamental para sua normatividade no Estado brasileiro.

No Brasil, é considerada como maior conquista para universo feminino a Lei de Enfrentamento a Violência Doméstica, Lei 11.340 de 7 de agosto de 2006, complementada com a nova Lei 14.022 de 7 de julho de 2020, que dispõe de medidas de enfrentamento à violência doméstica e familiar contra a mulher, incluindo as mulheres com deficiência.

A violência contra mulher acontece de forma maioritária no seu convício familiar, sendo praticada por pessoas com as quais ela mantém forte vínculo afetivo, tornando muito mais difícil uma tomada de decisão, seja sobre denúncia ou rompimento do ciclo de violência. Essa dificuldade se assevera vinculada à culpabilização da violência realizada pelos seus agressores. 
VOLOTÃO, Jaqueline dos Santos. Os Direitos Humanos e Mulheres Vítimas de Violência Doméstica em tempos de pandemia. Dignidade Re-Vista, v.7, n.12, jul 2021.

O conjunto de fatores aqui destacados remete a seguinte questão: a pandemia facilitou a conscientização do ciclo de violência ou realmente os casos aumentaram devido ao confinamento familiar?

A análise considerará a trajetória histórica do direito das mulheres e suas sustentações legais, baseada em pesquisa documental como apoio à pesquisa qualiquanti-tativa e método comparativo. Destaca mulher e sua histórica submissão aos homens frente à sociedade, o recente rompimento desse ciclo de submissão, assim como as conquistas das mulheres no mundo. Apontará marcos como o direito ao voto (1948), que representa grande avanço para que a sociedade olhasse para mulher como parte do todo. Com esse pontapé inicial, algumas convenções sobre direitos políticos, civis, de igualdade, entre outros, começaram a surgir e a modificar a postura da mulher na sociedade.

Mesmo com os avanços e conquistas, as mulheres ainda sofrem com abusos e violências, principalmente por pessoas de seus laços familiares. Outro marco é a Convenção Interamericana para Prevenir, Punir e Erradicar a Violência Contra Mulher, também conhecida como Convenção de Belém do Pará (1994), que assim definiu a violência contra a mulher: "qualquer ato ou conduta baseado nas diferenças de gênero que cause morte, dano ou sofrimento físico, sexual ou psicológico à mulher”. Logo após essa Convenção, ocorreram muitas mudanças nas leis brasileiras, sendo a mais conhecida a Lei Maria da Penha, que será também considerada neste artigo.

\section{As Leis de proteção à mulher e seus avanços}

\section{1 - Lei Maria da Penha}

A Lei 11.340 de 2006, também conhecida como Lei Maria da Penha, possui artigos voltados para eliminar todas as formas de discriminação contra a mulher, prevenir, punir e erradicar a violência de gênero, criando mecanismos no Código De Processo Penal para o cumprimento da Lei.

Esses artigos visam assegurar à mulher vítima de violência doméstica seus direitos básicos e fundamentais para sua restruturação na sociedade. Recomenda o desenvolvimento de políticas públicas para resguardar a integridade dessa mulher, além de propor medidas de prevenção.

Encontram-se nesta Lei formas de prevenção à atuação da autoridade policial, que deverá conduzir e tomar as devidas providências cabíveis diante do problema encontrado. 
VOLOTÃO, Jaqueline dos Santos. Os Direitos Humanos e Mulheres Vítimas de Violência Doméstica em tempos de pandemia. Dignidade Re-Vista, v.7, n.12, jul 2021.

$\mathrm{O}$ art. $7^{\circ}$ é um dos mais importantes, pois nele estão os diferentes tipos de violência que a mulher pode sofrer:

- A violência física - conduta que ofenda sua integridade ou saúde corporal;

- A violência psicológica - qualquer conduta que lhe cause dano emocional, como diminuição da autoestima, sendo realizada de formas diferentes, como: ameaça, perseguição, humilhação, chantagem, entre outras;

- A violência sexual - se refere a qualquer conduta que envolva ato sexual sem o consentimento da mulher, ou qualquer método contraceptivo forçado, assim como o aborto ou prostituição. Essa violência pode ser cometida por ameaça, chantagem ou mesmo manipulação;

- A violência patrimonial - qualquer conduta que configure retenção, subtração, destruição parcial ou total de seus objetos, valores e direitos ou recursos econômicos, incluindo os destinados a satisfazer suas necessidades;

- A violência moral - conhecida como calúnia, injuria e / ou difamação.

Além de tipificar as violências de uma forma didática, essa Lei se torna mais completa por também tratar da assistência à mulher em situação de violência, promovendo integração entre o Poder Judiciário, Ministério Público, Defensoria Pública, Segurança Pública, assistência social, saúde, educação, trabalho e habitação. Destaca-se a importância da promoção dos estudos e pesquisas buscando avaliar os resultados das medidas tomadas com periodicidade.

Também é importante realçar a preocupação com a promoção de programas educacionais com campanhas educativas de prevenção e informação sobre o que é violência, assim como o atendimento policial especializado para as mulheres que sofreram a violência.

Da mesma forma que a Lei traz a metodologia intersetorial de atuação entre os órgãos, valorizando o conhecer para melhor intervir, traz também as sanções, que estão assim organizadas:

- sanções restritivas aplicadas após a vítima realizar a denúncia contra o agressor, sendo aplicadas de acordo com o grau da violência e o risco eminente de morte, podendo levar o agressor à prisão imediatamente ou após um mandado.

- Medida Protetiva de Urgência, a mais utilizada, que costuma ser respeitada pelo agressor. Aquele que descumpre a solicitação de afastamento pode ter sua liberdade restrita, tendo que responder ao processo em regime fechado (preso).

$\mathrm{O}$ confinamento compulsório devido à pandemia contribuiu para o aumento dos casos de violência, fato comprovado pelo número de Medidas Protetivas e chamados ao 190. Houve 
VOLOTÃO, Jaqueline dos Santos. Os Direitos Humanos e Mulheres Vítimas de Violência Doméstica em tempos de pandemia. Dignidade Re-Vista, v.7, n.12, jul 2021.

também uma dificuldade de acesso às redes de proteção e denúncia, deixando essas mulheres ainda mais vulneráveis.

\section{2 - Lei do feminicídio}

Como a Lei Maria da Penha não possui um ou mais artigos específicos para os casos do agressor tentar contra a vida da mulher, ou tirar sua vida, a Lei 13.104 de março de 2015, altera o art. $121 \mathrm{CPP}$, para prever o feminicídio como crime hediondo, qualificando o homicídio contra a mulher por sua perspectiva de gênero. Constatada a causa do crime ou de sua tentativa, a pena é aumentada em 1/3 (um terço) até a metade se for praticado contra mulheres gestantes ou puérperas, meninas com menos de catorze anos e mulheres maiores de sessenta anos ou com deficiência.

Para o Código Penal Brasileiro, o feminicídio não é um crime novo, apenas é um agravante ao crime de homicídio, transformando a pena maior conforme as circunstâncias do crime praticado.

Em entrevista, a psicóloga do NUDEM, Pâmella Rossy Duarte, fala sobre sua percepção de aumentos de casos na pandemia, relatando que o isolamento social provocou uma vulnerabilidade maior das mulheres que já viviam o ciclo de violência, aumentando o número do ápice dessa violência, o feminicídio.

As mortes em razão de gênero aumentaram, em nosso país, cerca de 2\%, comparadas ao primeiro semestre de 2019/2020 (dados anteriores à pandemia). O Alto Comissariado das Nações Unidas pra os Direitos Humanos (ACNUDH) aponta o Brasil como $5^{\circ}$ lugar no ranking mundial de feminicídio. Isso reforça discriminação estrutural, desigualdade de gênero e de poder, que torna a mulher inferiorizada e subordinada aos homens na visão patriarcal das sociedades em geral.

Em março de 2021, o STF, por unanimidade, proíbe a tese de legítima defesa da honra em crimes de feminicídio, justamente por violar os princípios constitucionais da dignidade da pessoa humana, violando a proteção à vida e de igualdade de gênero. Dessa forma, esse argumento não pode ser utilizado em nenhuma fase pré-processual e processual.

Para dar mais sustentação à proibição, o STF adicionou regra do artigo 28 no Código Penal, onde diz: a emoção ou a paixão não excluem a imputabilidade penal. Para o Ministro Dias Toffoli, a prática do feminicídio ou o uso de violência não pode ter como justificativa a repressão de um adultério, não está a se defender, mas sim a atacar uma mulher de forma covarde e criminosa. 
VOLOTÃO, Jaqueline dos Santos. Os Direitos Humanos e Mulheres Vítimas de Violência Doméstica em tempos de pandemia. Dignidade Re-Vista, v.7, n.12, jul 2021.

Considera-se um avanço para proteção da mulher o entendimento do STF, em que a defesa do homem agressor não pode mais utilizar esse tipo de argumento para minimizar a pena ou mesmo extinguir a punabilidade.

\section{A violência doméstica na pandemia}

O Brasil não estava com sua economia estável quando a pandemia se instaurou, provocando ainda mais desempregos e desespero nas famílias vulneráveis. A desigualdade acentuada e o desequilíbrio emocional tornaram a convivência familiar mais dificultosa. Com esse olhar, percebemos uma das justificativas para a rapidez nas fases do ciclo da violência. $\mathrm{O}$ Instituto Maria da Penha descreve as fases do ciclo da violência de forma didática.

O comportamento do homem nas fases do ciclo da violência:

- Primeira fase: o homem apresenta um comportamento tempestivo, mostrando-se irritado, podendo começar a realizar ameaças e quebra de pequenos objetos que a mulher estima.

- Segunda fase: homem não consegue mais controlar seu comportamento violento, e ocorre a agressão.

- Terceira fase: o arrependimento do homem faz com que seu comportamento seja amável e busque a reconciliação.

O comportamento da mulher nas fases do ciclo da violência:

- Primeira fase: o comportamento da mulher costuma ser retraído, evitando inflamar a raiva do companheiro, mesmo que o medo tome conta de seus pensamentos. É nessa fase que a negação dos fatos ocorre, pelo simples desejo de não acreditar que realmente está acontecendo com ela, buscando justificativas em seu comportamento que justifiquem as reações do parceiro.

- Segunda fase: a mulher se sente paralisada com a atitude final e, sem conseguir reagir ao ato de violência, seus sentimentos tornam-se um misto de ódio, solidão, vergonha e dor.

- Terceira fase: a mulher, mesmo que desconfiada, aceita a reconciliação com as lembranças dos momentos bons que tiveram juntos.

Tempo de cada fase:

- Essa primeira fase não possui um tempo pré-determinado, podendo durar horas, dias ou anos para chegar à segunda fase. 
VOLOTÃO, Jaqueline dos Santos. Os Direitos Humanos e Mulheres Vítimas de Violência Doméstica em tempos de pandemia. Dignidade Re-Vista, v.7, n.12, jul 2021.

- $O$ ato de violência, realizado na segunda fase, não possui um tempo estabelecido, mas é a pior fase para a mulher, pois suas reações são completamente adversas, ou seja, cada mulher pode reagir de formas diferentes, como procurar ajuda, se esconder ou mesmo se matar. Essa tomada de decisão depende exatamente do tempo que a primeira fase durou e o que ela sofreu (violência verbal, psicológica, patrimonial).

- A aproximação estreita a relação de dependência entre vítima e agressor.

Assim como na primeira fase, em que não temos como precisar o tempo, na terceira fase também não se tem como mensurar quanto tempo demora a que voltem a acontecer os episódios da primeira fase, concretizando o que chamamos de ciclo de violência doméstica.

É importante mencionar que o ciclo pode ser rompido em qualquer fase, porém é mais comum que o seu rompimento aconteça após um longo período da fase um e na fase dois. Isso acontece após a mulher já ter passado por mais de uma vez nesse ciclo completo.

O ciclo da violência é conhecido pelas características marcantes de suas três fases distintas, que no período da pandemia passou a ter durações menores de uma fase para outra, intensificado o aumento da tensão ao ato de violência. Percebemos que os ciclos foram rompidos mais facilmente nesse período pandêmico, justamente pelo agravamento do isolamento social, pois essas mulheres tendem a ficar presas com seus agressores. A última fase, que chamamos de fase do arrependimento, passou a ser menos observada pelos profissionais da ponta.

\section{Olhar dos Direitos Humanos}

Os Direitos Humanos defendem em seus artigos o direito à vida, que vem ao encontro, entre outras leis, da Lei do Feminicidio (Lei 13.104/15), que vem para punir aqueles que tentam contra a vida da mulher devido a seu gênero, ou mesmo conclui o fato levando ao óbito. Além disso, em seus artigos, os Direitos Humanos deixam claro sua posição contra a violência, tortura, discriminação, vistas constantemente na Lei Maria da Penha.

Portanto, pode-se afirmar que as leis propostas em favor da vida da mulher "beberam" na fonte dos artigos dos Direitos Humanos (1948). Além disso, eles são norteadores de normas internacionais que obrigam os governos a adotarem medidas de prevenção e erradicação da violência de gênero, pelo desrespeito à dignidade humana.

A pandemia se tornou um período propício para violação dos direitos humanos e aumento de casos da violência contra mulheres, aumentando também a vulnerabilidade alimentícia das famílias. 
VOLOTÃO, Jaqueline dos Santos. Os Direitos Humanos e Mulheres Vítimas de Violência Doméstica em tempos de pandemia. Dignidade Re-Vista, v.7, n.12, jul 2021.

Em meio à calamidade da saúde pública, o Governo Federal busca conter a violência doméstica através de novas regras na Lei 14.022, de 7 de julho de 2020:

Art. $1^{\circ}$ Esta Lei dispõe sobre medidas de enfrentamento à violência doméstica e familiar contra a mulher e de enfrentamento à violência contra crianças, adolescentes, pessoas idosas e pessoas com deficiência durante a emergência de saúde pública de importância internacional decorrente do coronavírus responsável pelo surto de 2019.

Essas novas regras chegam com o intuito de minimizar a violação dos direitos fundamentais das mulheres, buscando proteção e auxílio imediato da rede de enfrentamento.

\section{Núcleo Especial de Direito da Mulher e de Vítimas de Violência de Gênero (NUDEM)}

A Defensoria Pública do Rio de Janeiro realiza atendimento às mulheres vítimas de violência de gênero há quase 23 anos através do NUDEM - de forma acolhedora, buscando entender suas necessidades e informar seus direitos. É um Núcleo de primeiro atendimento que se tornou referência no Estado por sua excelência no atendimento a essas mulheres.

O Núcleo é constituído por uma equipe especializada em atendimento às mulheres vítimas de violência, com a presença de Defensora Pública exclusiva para o órgão e uma equipe técnica (assistente social e psicóloga) para que possa dar o suporte a toda necessidade da mulher que chega para o atendimento.

O atendimento é realizado de acordo com a necessidade da mulher, seja para orientação jurídica e realização de processos referentes à guarda e regulamentação de visita de seus filhos, alimentos, divórcio, queixa-crime, indenização, entre outras ações, sejam encaminhamentos para a rede de atendimento para dar o suporte psicossocial à mulher que é vítima de violência de gênero.

Em tempos de pandemia, o Núcleo se reestruturou para manter o bom atendimento às mulheres que chegam a grande número diariamente. Assim, com o atendimento chamado "funcional", as vítimas de violência entram em contato pelo aplicativo WhatsApp, seja por encaminhamento da rede de atendimento ou pelo simples fato de pesquisarem o contato no site da Defensoria Pública.

O atendimento Funcional é realizado por duas servidoras do quadro que recebem orientação das Defensoras Públicas designadas para atuação no órgão. Elas fazem o chamado primeiro atendimento, quando verificam se o caso daquela vítima é do NUDEM ou de outro 
VOLOTÃO, Jaqueline dos Santos. Os Direitos Humanos e Mulheres Vítimas de Violência Doméstica em tempos de pandemia. Dignidade Re-Vista, v.7, n.12, jul 2021.

órgão, realizando seu encaminhamento. É comum a mulher apenas entrar em contato para saber do andamento da Medida Protetiva ou solicitar sua renovação, sendo encaminhada para o Juizado de Violência Doméstica que atende seu bairro.

Quando é identificado que a mulher necessita do atendimento para além das medidas protetivas que já estão em vigor, ou que a mulher não possui essa medida protetiva e gostaria de solicitar, ela é encaminhada para as servidoras do "remoto". O atendimento remoto consiste em escutar a mulher, buscar todas as informações pertinentes aos processos que ela gostaria serem esclarecidos, como os processos falados anteriormente, e encaminhar para as estagiárias e Defensoras para iniciar a petição.

A mulher vítima em atendimento também pode receber mensagens das estagiárias para maiores esclarecimentos ou envios de mais documentos que possam ser necessários ao seu processo, pensando em deixar uma inicial perfeita para a distribuição nas Varas de Família do bairro.

A Equipe Técnica é acionada sempre que necessários encaminhamentos à rede de atendimento especializada, ou mesmo fortalecer aquela mulher para tomada de decisão. Em alguns casos, são necessários os relatórios da equipe para complementar as ações.

O NUDEM também interage com os outros órgãos da Defensoria Pública, como os Juizados de Violência Doméstica da região (bairro ou município) em que a mulher mora, de forma que os Defensores designados conheçam de forma mais rápida a demanda que a mulher relata.

A atuação do NUDEM é de Núcleo de primeiro atendimento, ou seja, não pode atuar em processos que já existem, como é o caso de Medidas Protetivas de Urgência que já foram solicitadas anteriormente. Sua atribuição é realizar novas ações em favor da vítima, encaminhando ao final a distribuição para as Varas de Família Civis, por exemplo.

\section{Redes de atendimento à Mulher Vítima de Violência em tempos de pandemia}

A mulher vítima de violência possui uma rede de atendimento especializada com atuação focada em auxiliá-la na ruptura do ciclo de violência. No nível nacional, existe a Secretaria de Políticas para as Mulheres (SPM), junto à Presidência da República, criada em 2003, responsável pelas diretrizes do Pacto Nacional de Enfrentamento à Violência contra as Mulheres, assim como a constituição e fortalecimento compreendidos no I e II Planos Nacionais de Políticas para as Mulheres (PNPM, Brasília 2008). 
VOLOTÃO, Jaqueline dos Santos. Os Direitos Humanos e Mulheres Vítimas de Violência Doméstica em tempos de pandemia. Dignidade Re-Vista, v.7, n.12, jul 2021.

Após a criação dessa Secretaria que pode fortalecer a rede de atendimento à mulher nos estados e municípios, esses também criaram suas secretárias e formas de atendimento para esse público, de forma a atender as estratégias e articulações previstas na Lei Orgânica da Assistência Social, entre outras normas e políticas de proteção emergencial.

Com base na Lei Orgânica de Assistência Social (Lei 8.742/1993, atualizada em 2011 por meio da Lei 12.435) a política de Assistência Social é reconhecida como dever de Estado, Direito do Cidadão, organizada por meio de proteção social, vigilância socioassistencial e defesa e garantia de direitos, ofertada à população por meio de serviços e benefícios, programas e projetos. Oos serviços organizados são responsabilidade dos entes federativos, definindo a importância da prestação de Serviço Centro de Referência de Assistência Social (CRAS), sendo obrigatória ao menos uma unidade por município, assim como é indicada a instalação de Centro de Referência Especializado de Assistência Social (CREAS).

Ambas as unidades públicas estatais devem estar compatíveis com serviços prestados no que rege a Lei Orgânica, assegurando o bom atendimento e a acessibilidade. O CREAS atende de forma mais especializada pessoas que tem situações comprovadas de risco, ou seja, vítimas de violência.

O Centro Integrado de Atendimento à Mulher (CIAM) e o Centro Especializado de Atendimento à Mulher (CEAM), segundo o Conselho Estadual dos Direitos da Mulher do Estado do Rio de Janeiro, foram criados para atender as mulheres vítimas de violência de gênero, podendo analisar os casos de necessidade de abrigamento. Eles não estão presentes em todos os municípios, assim como não são todas as cidades que possuem um Conselho Municipal dos Direitos da Mulher, sendo, nesse caso, incorporados pelas Secretarias Municipais de Assistência Social e Direitos Humanos (SMASDH).

Logo no início da pandemia da Covid-19, os Centros de Referência divulgaram números de telefones para atendimento remoto, e os casos mais graves que necessitavam de abrigamento eram recebidos presencialmente. Atualmente, o atendimento ainda está de forma híbrida, ou seja, atendendo tanto de forma remota quanto presencial.

\section{Dados quantitativos como estratégia para intervenções}

As iniciativas públicas de intervenção no âmbito da proteção social terão em suas ações maior efeito positivo se amparadas por informações. Nesse sentido, a busca por dados quantitativos, que são importantes aliados. Esse entendimento é inspirador para a criação de 
VOLOTÃO, Jaqueline dos Santos. Os Direitos Humanos e Mulheres Vítimas de Violência Doméstica em tempos de pandemia. Dignidade Re-Vista, v.7, n.12, jul 2021.

mecanismos para agilizar o fluxo de informação e as respectivas intervenções. Dentre esses mecanismos é possível destacar:

- Disque 100 é um canal de atendimento utilizado pelos Direitos Humanos para denúncia das violações de direitos humanos em grupos vulneráveis, quantificando os diferentes tipos de violência.

- Disque 180 é um canal exclusivo para violência contra mulher, que, além de registrar as informações, as encaminha para os órgãos competentes de cada região do país. O serviço fornece, ainda, informações sobre os direitos da mulher, encaminhando-as para os locais adequados para o atendimento presencial ou remoto.

Ao realizar as pesquisas sobre registros de ocorrências de violência contra a mulher no período da pandemia, foi identificada uma redução nos números de registros comparando com o mesmo período em 2019. Essa informação traz à reflexão as possíveis razões, e uma das possibilidades dessa redução pode ser a dificuldade de acesso à unidade policial. Isso porque houve um aumento no Serviço da Polícia Militar, chamado 190, direcionado aos crimes contra mulher.

Avaliando o quadro comparativo abaixo, com os dados de atendimento do NUDEM às mulheres vítimas de violência, podemos observar o aumento considerável após a implementação do telefone funcional, em maio de 2020, o que nos leva a confirmar que as dificuldades de acesso ao serviço policial foram decisivas no processo.

Quadro 1 - Comparação do número de atendimentos 2019/2020

\begin{tabular}{|l|r|}
\hline \multicolumn{2}{|c|}{2019} \\
\hline MÊS & $\begin{array}{c}\text { TOTAL DE } \\
\text { ATENDIMENTO }\end{array}$ \\
\hline JANEIRO & 278 \\
\hline FEVEREIRO & 287 \\
\hline MARÇO & 249 \\
\hline ABRIL & 275 \\
\hline MAIO & 304 \\
\hline JUNHO & 240 \\
\hline JULHO & 278 \\
\hline AGOSTO & 278 \\
\hline SETEMBRO & 114 \\
\hline OUTUBRO & 274 \\
\hline NOVEMBRO & 261 \\
\hline DEZEMBRO & 173 \\
\hline TOTAL & 3011 \\
\hline
\end{tabular}

\begin{tabular}{|l|r|}
\hline \multicolumn{2}{|c|}{2020} \\
MÊS & $\begin{array}{c}\text { TOTAL DE } \\
\text { ATENDIMENTO }\end{array}$ \\
\hline JANEIRO & 182 \\
\hline FEVEREIRO & 187 \\
\hline MARÇO & 99 \\
\hline ABRIL & 390 \\
\hline MAIO & 525 \\
\hline JUNHO & 576 \\
\hline JULHO & 572 \\
\hline AGOSTO & 560 \\
\hline SETEMBRO & 588 \\
\hline OUTUBRO & 582 \\
\hline NOVEMBRO & 494 \\
\hline DEZEMBRO & 448 \\
\hline TOTAL & 4755 \\
\hline
\end{tabular}

Fonte: elaborado pela equipe do NUDEM

Ao entrevistar as servidoras que atuam na ponta do atendimento à mulher no NUDEM, são unânimes as respostas quanto à barreira física que antes existia. Elas relatam que, antes da pandemia ,o atendimento era realizado, em sua grande maioria, a mulheres que moravam na redondeza do Centro da Cidade do Rio de Janeiro, ou aquelas que por lá trabalhavam. Com o 
VOLOTÃO, Jaqueline dos Santos. Os Direitos Humanos e Mulheres Vítimas de Violência Doméstica em tempos de pandemia. Dignidade Re-Vista, v.7, n.12, jul 2021.

atendimento remoto, passou a atender mulheres de bairros, cidades e regiões que nunca antes haviam sido atendidas, como os municípios de Barra Mansa, Valença, Varre-Sai, entre outros.

\section{Algumas considerações}

A Pandemia, de fato, trouxe algumas reflexões sobre o agravamento da violência doméstica, o rompimento do ciclo de violência, o atendimento das mulheres pelos órgãos competentes. $\mathrm{O}$ aumento dos casos mostra como as mulheres permanecem vulneráveis frente ao homem e as dificuldades do rompimento do ciclo da violência perpassa apenas a questão financeira.

Foi percebido que o atendimento da Polícia Civil foi reduzido, assim como seu acesso ao registro de ocorrência foi limitado. Durante muitos meses nesse período de pandemia, as delegacias estavam com atendimento apenas de crimes em flagrante. Caso a mulher estivesse sendo agredida e um policial militar fizesse a prisão em flagrante, a Delegacia aceitava a denúncia. As denúncias que não eram em flagrante eram realizadas pelo site específico de denúncias da Polícia Civil. Mas os números de medidas protetivas aumentaram, em conjunto com as demandas dos órgãos que fazem o atendimento à mulher.

A limitação da denúncia de forma virtual nas Delegacias deixa a desejar, por sua forma fria de um sistema eletrônico, diferente do que acontece com o atendimento do NUDEM, com seu atendimento remoto e acolhedor. Nessas horas a atuação da rede de atendimento é essencial para o apoio dessa mulher, orientando cada passo que deve ser tomado, fortalecendo seu aspecto psicológico para continuar o rompimento do ciclo de violência.

O trabalho do NUDEM vem para complementar o atendimento da rede, pois não possui "braços" para auxiliar todas as mulheres que relatam casos de violência e não conseguem realizar o registro de ocorrência de forma remota. Os direitos da mulher e de sua prole são garantidos independentemente de um registro de ocorrência, quando se consegue identificar a violência sofrida e realizar o acolhimento daquela mulher.

A violência contra mulher possui índice crescente em nossa sociedade, mesmo após a criação de leis protetivas, e com o confinamento familiar devido à pandemia, esse índice aumentou. $\mathrm{O}$ ciclo da violência se intensifica e as mulheres tendem a ficar mais vulneráveis, mas procuram caminhos para o fortalecimento emocional e enfim romper os laços com seu agressor. 


\section{Referências bibliográficas}

BERQUÓ, Thirzá Amaral. Entre as heroínas e o silêncio: a condição feminina na Atenas Clássica. I Encontro de Pesquisas Históricas. Porto Alegre: PUCRS, 2014.

BRASIL. Lei $\mathrm{n}^{\circ}$ 11.340, DE 7 de agosto de 2006. Cria mecanismos para coibir a violência doméstica e familiar contra a mulher, nos termos do $\S 8^{\circ}$ do art. 226 da Constituição Federal (...) Diário Oficial da União, Brasília,2006.

BRASIL. Lei no 13.104 DE 9 de março de 2015. Altera o art. 121 do Decreto-Lei $\mathrm{n}^{\circ} 2.848$, de 7 de dezembro de 1940 - Código Penal, para prever o feminicídio como circunstância qualificadora do crime de homicídio. Diário Oficial da União, Brasília, 2015.

BRASIL. Lei ${ }^{\circ} 14.022$ de 7 de julho de 2020. Altera a Lei ${ }^{\circ} 13.979$, de 6 de fevereiro de 2020, e dispõe sobre medidas de enfrentamento à violência doméstica e familiar contra a mulher em tempos de pandemia. Diário Oficial da União, Brasília, 2020.

CÂMARA MUNICIPAL DE SP. Pandemia proporcionou casos de violação de Direitos Humanos. Disponível em: https://www.saopaulo.sp.leg.br/coronavirus/blog/pandemiapropiciou-casos-de-violacao-de-direitos-humanos/ Acesso em: 4 abr 2021.

CONSELHO ESTADUAL DOS DIREITOS DA MULHER / RJ. Disponível em: http://arquivos.proderj.rj.gov.br/cedim_imagens/SCSEditaImprensa/arquivos/uploads/CEAM \%20lista\%20RJ\%20atualizada.pdf

CRANSTON, Maurice. O que são os direitos humanos? Rio de Janeiro: DIFEL, 1979.

INSTITUTO MARIA DA PENHA. Disponível em: https://www.institutomariadapenha.org.br/violencia-domestica/ciclo-da-violencia.html Acesso em 4 abr 2021.

NOTÍCIAS STF. STF proíbe uso da tese de legítima defesa da honra em crimes de feminicídio. Disponível em: http://stf.jus.br/portal/cms/verNoticiaDetalhe.asp?idConteudo=462336 Acesso em: 4 fev 2021.

SERVIÇO DE ASSISTÊNCIA SOCIAL - Rede de Assistência e Proteção Social. Disponível em: $\quad$ https://www.gov.br/pt-br/servicos/denunciar-e-buscar-ajuda-a-vitimas-de-violenciacontra-mulheres Acesso em: 1 abr 2021. 